\title{
Investigation of the comorbidity of dissociative disorders in patients with bipolar disorder
}

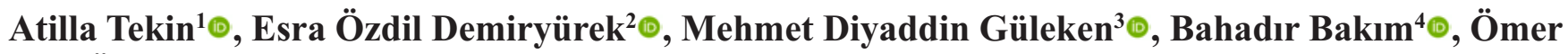 \\ Akil Özer ${ }^{5}$, Oğuz Karamustafalığlu ${ }^{5} \odot$
}

${ }^{1}$ Department of Psychology, Haliç University, Faculty of Arts and Sciences, Istanbul, Turkey

${ }^{2}$ Department of Psychiatry, Sakarya Training and Research Hospital, Sakarya, Turkey

${ }^{3}$ Department of Psychiatry, Gazi Yaşargil Training and Research Hospital, Diyarbakur, Turkey

${ }^{4}$ Department of Psychiatry, Yeni Yüzyll University School of Medicine, Istanbul, Turkey

${ }^{5}$ Department of Psychiatry, Şişli Hamidiye Etfal Training and Research Hospital, Istanbul, Turkey

DOI: $10.18621 /$ eurj.412272

\begin{abstract}
Objectives: The aim of this study was to investigate the comorbidity of dissociative disorders in patients with bipolar disorder.

Methods: Fifty-one patients who are diagnosed with bipolar disorder in euthymic state and forty-nine healty controls were included in the study. The Structured Clinical Interview for DSM-IV Axis I Disorders (SCID-I), Structured Clinical Interview for DSM-IV Dissociative Disorders (SCID-D), Dissociative Experiences Scale (DES) and Childhood Trauma Questionnaire (CTQ-28) were administered to all participants with a sociodemographic form.

Results: Mean DES and CTQ-28 total scores were statistically higher in patients group than control group ( $p$ $<0.001$ and $p<0.001$, respectively). Emotional abuse, emotional neglect, physical abuse, physical neglect and sexual abuse subscale scores of CTQ-28 were higher in patients group than healthy controls group ( $p=$ $0.002, p<0.001, p=0.005, p<0.001$ and $p<0.021$, respectively). The rate of any dissociative disorder comorbidity was $35.4 \%$ in patients with bipolar disorder. The most frequent dissociative disorder in patient with bipolar disorder was depersonalization disorder (17.6\%). There was a positive correlation between DES score and number of suicidal attempts $(\mathrm{r}=0.284)$. Negative correlations were found between DES score and age of disease onset, and CTQ-28 total score and age of disease onset $(r=-0.332$ and $r=-0.291)$.

Conclusion: Our results have shown that dissociative disorders may be frequently accompanied in patients with bipolar disorder. Dissociation and childhood traumatic events can be related with clinical features in patients with bipolar disorder.
\end{abstract}

Keywords: childhood trauma, dissociation, bipolar disorder

Received: April 3, 2018; Accepted: May 2, 2018; Published Online: June 22, 2018

$\mathrm{T}$ raumatic experiences during childhood are frequently emphasized in the aetiology of bipolar disorder as well as many other psychiatric disorders. In bipolar patients with a history of childhood trauma,

studies have shown that the age of disease onset age is earlier, the number of affective episodes is higher, the rate of rapid cycling is increased and psychotic symptoms as well as suicide attempts are more

Address for correspondence: Atilla Tekin, MD., Assist. Prof., Haliç University, Faculty of Arts and Sciences, Department of Psychology, Istanbul, Turkey, E-mail: md.atillatekin@gmail.com, Phone: +90212 9242444,Fax:+90212999787852 
common [1-8].

Dissociation, which is characterized with changes in or deterioration of the normal integrative functions of memory, identity and consciousness, manifests in many psychiatric disorders. Some studies have demonstrated dissociative symptoms to be present in psychotic disorders such as schizophrenia, anxiety disorders and in borderline personality disorders and that there is a relationship between childhood traumatic experiences and dissociative symptoms. It seems that the comorbidity of dissociative disorder is related with poor prognostic features in other psychiatric disorders $[9,10]$. However, it is notable that the dissociative disorders in bipolar disorders have been less evaluated in literature $[11,12]$.

We hypothesized that dissociative disorders may be accompanied in patients with bipolar disorders frequently, and comorbidity of dissociative disorders is related with poor clinical features in patients with bipolar disorder. The primary aim of this study was to investigate the comorbidity rate of dissociative disorders in patients with bipolar disorder. The second aim of the study was to investigate the relationship between dissociation and childhood traumas, and clinical features in patients with bipolar disorder.

\section{METHODS}

This study included 51 bipolar patients in a euthymic state, who had previously been diagnosed according to the DSM-IV-TR diagnostic criteria, who were being followed at Şişli Hamidiye Etfal Training and Research Hospital Psychiatry Outpatient Clinic, and 49 healthy volunteers with no psychiatric diagnosis. The research protocol was approved by the Şişli Hamidiye Etfal Education and Research Hospital Ethics Committee. Each study participant signed an informed consent form that was approved by the ethics committee. The research was carried out in accordance with the World Medical Association Code of Ethics for Medical Research Involving Human Subjects Declaration of Helsinki Good Clinical Practice Guidelines.

\section{Patients}

The patient group of this study were volunteer euthymic individuals between the ages $18-65$, at least primary school graduates, had no severe neurologic and internal diseases, had no current other Axis-I diagnosis, did not have coexisting schizophrenia or any other psychotic disorder, had no alcohol or substance addiction or abuse and had been diagnosed as bipolar according to the DSM-IV diagnostic criteria. Excluding criteria for the patient group included those younger than 18 years and older than 65 years of age, illiterate individuals, those with severe neurologic or internal disease and those with alcohol or substance abuse or addiction.

\section{Clinical evaluation}

Each participant who volunteered to participate in this study was asked to fill out a sociodemographics data form, a Childhood Traumatic Questionnaire (CTQ) and a Dissociative Experiences Scale (DES). The Structured Clinical Interview for DSM-IV Axis I Disorders (SCID-I) and Structured Clinical Interview for DSM-IV Dissociative Disorders (SCID-D) was applied by the interviewer to each participant.

SCID-I is a clinical interview structured by First et al. [13] for DSM-IV Axis I disorders. The adaptation and reliability studies of SCID-I for Turkey were performed by Çorapçığlu et al. [14]. SCID-D is a structured clinical interview chart for DSM-IV dissociative disorders developed by Steinberg [15]. It can be used to evaluate the dissociative symptoms and disorders of the subject in various psychiatric diseases. The reliability and validity studies for Turkey have been conducted by Kundakçı et al. [16].

DES is a scale consisting of 28 items developed by Bernstein and Putnam [17]. For each item of the scale, subjects give points between $0-100$ and the result is obtained by calculating the average of the total scores. Total scores that are higher than 30, are indicative of a dissociative disorder. The reliability and validity studies for Turkey were performed by Yargiç et al. [18]. CTQ was developed by Bernstein et al. [19]. It is a self- reported quintet Likert type scale. It includes questions for evaluating childhood emotional, physical and sexual abuse and physical and emotional neglect. The reliability and validity studies for Turkey were performed by Şar et al. [20].

\section{Statistical Analysis}

Statistical analyses of the present study were performed with the SPSS 16.0 program. Descriptive 
Table 1. Comparison of the sociodemographic features of the patients and control groups

\begin{tabular}{llccc}
\hline Variable & & $\begin{array}{c}\text { Patient Group } \\
(\mathbf{n}=\mathbf{5 1})\end{array}$ & $\begin{array}{c}\text { Control Group } \\
(\mathbf{n}=\mathbf{4 9})\end{array}$ & $\boldsymbol{p}$ value \\
\hline Age (years) & & $35.1 \pm 10.19$ & $37.1 \pm 9.1$ & $0.363^{1}$ \\
Gender & Female & $26(51)$ & $29(59.2)$ & $0.410^{2}$ \\
& Male & $25(49)$ & $20(40.8)$ & \\
Education & Primary- & $16(31.4)$ & $16(32.7)$ & $0.721^{2}$ \\
& Secondary & & & \\
& High & $23(45.1)$ & $18(36.7)$ & \\
Maritalstatus & University & $12(23.5)$ & $15(30.6)$ & \\
& Married & $26(51)$ & $32(65.3)$ & $0.310^{2}$ \\
Smoking & Single & $25(49)$ & $17(34.7)$ & \\
Alcohol consumption & (Have) & $22(43.1)$ & $23(46.9)$ & $0.702^{2}$ \\
\hline
\end{tabular}

Data are shown as mean \pm standard deviation or number $(\%)$. ${ }^{1}$ independentsample $t$ test, ${ }^{2}$ Chi-square test

statistics were given as frequency, percentage, mean, standard deviation, and minimum-maximum. values. Differences between categorical variables in the groups were analyzed with the Chi-square test. Normality assessment of the continuous variables was performed with Shapiro-Wilk test. Comparisons of the variables that fitted normal distribution were evaluated with the Student's t-test. The correlation between the variables of the patient group was evaluated with the Spearman nonparametric test. Results were evaluated at a $p<0.05$ level of significance.

\section{RESULTS}

There is no difference on age between the patients and controls groups $(35.1 \pm 10.19$ years and $37.1 \pm 9.1$ years, respectively) $(p=0.363)$. There was no statistically significant difference between the patient and control groups of the study in terms of sociodemographic data (Table 1). The mean age of the disease onset in patients with bipolar disorder was $24.41 \pm 4.37$ years. The mean number of hospitalization of the patients was $3.39 \pm 1.03$. The mean number of suicide attempts of the patients was $1.71 \pm 0.44$.

CTQ-28 total, emotional abuse, emotional neglect, physical abuse, physical neglect and sexual abuse subscale scores were higher in patients group than healthy control group $(p<0.001, p=0.002, p<0.001$, $p=0.005, p<0.001$ and $p<0.021$; respectively). Mean DES score of the patients group was higher than the healthy controls (Table 2).

The most prevalent dissociative disorder was

Table 2. Comparison of DES and CTQ-28 scales scores betwee the patients and controls group.

\begin{tabular}{lccc}
\hline Scale & $\begin{array}{c}\text { Patient Group } \\
(\mathbf{n}=\mathbf{5 1})\end{array}$ & $\begin{array}{c}\text { Control Group } \\
(\mathbf{n = 4 9 )}\end{array}$ & $\boldsymbol{p}$ value \\
\hline CTQ-Emotional abuse & $7.90 \pm 3.36$ & $6.20 \pm 1.47$ & 0.002 \\
CTQ-Emotional neglect & $10.16 \pm 4.17$ & $7.10 \pm 2.19$ & $<\mathbf{0 . 0 0 1}$ \\
CTQ-Physicalabuse & $6.67 \pm 2.98$ & $5.39 \pm 0.95$ & 0.005 \\
CTQ-Physical neglect & $7.61 \pm 2.85$ & $5.47 \pm 0.84$ & $<\mathbf{0 . 0 0 1}$ \\
CTQ-Sexual abuse & $6.59 \pm 3.70$ & $5.33 \pm 0.85$ & 0.021 \\
CTQ-total & $38.92 \pm 12.45$ & $29.57 \pm 5.07$ & $<\mathbf{0 . 0 0 1}$ \\
DES & $20.73 \pm 15.09$ & $7.13 \pm 4.54$ & $<\mathbf{0 . 0 0 1}$ \\
\hline
\end{tabular}

Data are shown as mean \pm standard deviation. CTQ $=$ Childhood Traumatic Questionnaire, DES = Dissociative Experiences Scale 
Table 3. Comorbid dissociative disorders in patients with bipolar disorder (by using SCID-D)

\begin{tabular}{lc}
\hline Dissociative Disorders & $\begin{array}{c}\text { Data } \\
\mathbf{n}(\mathbf{\%})\end{array}$ \\
\hline Dissociative amnesia & $4(7.8 \%)$ \\
Dissociative fugue & $1(1.9 \%)$ \\
Dissociative idendity disorder & $2(3.9 \%)$ \\
Depersonalization disorder & $9(17.6 \%)$ \\
Dissociative disorder not otherwise & $8(15.6 \%)$ \\
specified & \\
\hline
\end{tabular}

depersonalization disorder in patients with bipolar disorder (17.6\%). Other comorbid dissociative disorders in patients with bipolar were shown at the Table 3.

There was a positive correlation between DES score and number of suicidal attempt $(\mathrm{r}=0.284)$. A negative relationship was found between DES score and age of the disease $(r=-0.332)$. Emotional neglect score was correlate with number of suicide attempt and age of the disease onset $(r=0.328$ and $r=-0.333)$. CTQ-total score was negatively correlate with age of the disease onset $(r=-0.291)$ (Table 4).

\section{DISCUSSION}

The primary aim of the present study was to investigate the comorbidity of dissociative disorders in patients with bipolar disorder. The second aim of the study was to investigate the relationship between dissociation and childhood traumatic events, and clinical features of the patients.

Many studies have emphasized the relationship between bipolar disorder and childhood trauma [2124]. In a study conducted by Garno et al. [24], it has been reported that there are at least one type of childhood trauma in almost half of bipolar patients and two or more types in about one third of them. In a study conducted by Leboyer et al. [22], bipolar patients and healthy individuals were compared for childhood traumatic experiences. According to their results, while the incidence of at least one type of childhood trauma in bipolar patients was $54.4 \%$, this incidence was found to be $31.9 \%$ in healthy individuals [22]. The results of our study are similar to those of other studies in literature. Indeed, according to the results of our study, each CTQ subscale score (emotional abuse, physical abuse, physical neglect, emotional neglect and sexual abuse) was significantly higher in patients with bipolar disorder than in the healthy volunteers. The fact that childhood traumas are seen more frequently in bipolar patients brings to mind the question of how these childhood traumas affect the clinical course. Many studies have shown that there is a relationship between childhood trauma and the early age of disease onset, more suicidal attempts, more psychotic symptoms, higher rates of rapid cycling and more substance abuse in patients with bipolar disorder [6, 23-26]. Leverich et al. [26] have indicated that there is a relationship between physical and sexual abuse with early age of disease onset, rapid cycling and increased suicidal attempts in patients with bipolar disorder. Garno et al. [24] have found that in bipolar patients with childhood trauma, the age of disease onset was earlier and that patients with a history of sexual abuse were found to have more suicidal attempts. In a study conducted by Brown et al. [6], it has been found that the number of hospitalizations is higher in bipolar patients with childhood trauma and alcohol abuse was more in those with a history of sexual and physical abuse. Romero et al. [27] have found that there is more suicidal attempts and substance abuse in bipolar patients with

Table4. Correations of DES and CTQ-28 scale scores with clinical features in patients with bipolar disorder

\begin{tabular}{|c|c|c|c|c|c|c|c|}
\hline & $\overline{\text { DES }}$ & $\begin{array}{c}\text { Emotional } \\
\text { Abuse }\end{array}$ & $\begin{array}{c}\text { Emotional } \\
\text { Neglect }\end{array}$ & $\begin{array}{c}\text { Physical } \\
\text { Abuse }\end{array}$ & $\begin{array}{l}\text { Physical } \\
\text { Neglect }\end{array}$ & $\begin{array}{l}\text { Sexual } \\
\text { Abuse }\end{array}$ & $\begin{array}{c}\text { CTQ-28 } \\
\text { Total }\end{array}$ \\
\hline $\begin{array}{l}\text { Number of } \\
\text { Hospitalization }\end{array}$ & $\mathrm{r}=0.148$ & $\mathrm{r}=0.139$ & $\mathrm{r}=0.106$ & $\mathrm{r}=0.002$ & $\mathrm{r}=0.048$ & $\mathrm{r}=0.155$ & $\mathrm{r}=0.097$ \\
\hline $\begin{array}{l}\text { Number of } \\
\text { SuicideAttempt }\end{array}$ & $\mathrm{r}=0.284 *$ & $\mathrm{r}=0.106$ & $\mathrm{r}=0.328 *$ & $\mathrm{r}=0.092$ & $\mathrm{r}=0.046$ & $\mathrm{r}=0.205$ & $\mathrm{r}=0.219$ \\
\hline Age of Onset & $r=-0.332 *$ & $r=-0.264$ & $r=-0.333 *$ & $r=-0.174$ & $r=-0.029$ & $\mathrm{r}=-0.240$ & $r=-0.291 *$ \\
\hline
\end{tabular}


childhood trauma. According to the results of the present study, CTQ-28 total and emotional neglect subscale scores are correlated with early onset of the disease. Additionally, we have found that emotional neglect score was positively correlate with number of suicidal attempt in patients with bipolar disorder. The negative effects of childhood trauma on the clinical course of bipolar disease may be associated with various neurobiological impairments. Indeed, it has been demonstrated that childhood traumas leads to disruptions in the sensitivity of the neuroendocrine stress response and activity of the hypothalamicpituitary-adrenal axis and damages in the cortical areas such as the hippocampus and amygdala that have an important role in cognitive and emotional functions $[4,28,29]$.

There are less studies in literature that investigate the relationship between bipolar disorder and dissociation. In a study conducted by Latalova et al. [11], bipolar patients and healthy individuals were compared for level of dissociation. Latalova et al. [11] have found that DES score was higher in patients with bipolar disorder than healthy controls. Coryell [30] reported in a case report that multiple personality may occur as an epiphenomenon of the affective disorder or of other illnesses. Steingard and Frankel [31] reported a patient with a diagnosis of bipolar disorder, rapid cycling type, who in fact was experiencing dissociative episodes manifested as psychotic states. We have found that the mean DES score of the patients with bipolar disorder was higher than healthy controls. The most important result of the present study is that dissociative disorders are frequently accompanying to bipolar disorder. According to our results, the most prevalent dissociative disorders that accompanied to bipolar disorder are depersonalization disorder and dissociative disorder not otherwise specified (17.6\% and $15.6 \%$, respectively).

According to the results of the previous studies, it can be said that higher levels of dissociation has negatively affect the clinical course of bipolar disorder. Latalova et al. [11] have found that there is a relationship between higher levels of dissociation and earlier onset of the disease in patients with bipolar disorder. Spitzer et al. [32] have demonstrated lower treatment responses in bipolar patients with high dissociation scores. Bakim et al. [33] have found the relationship between higher DES scores and duration hospital stay in patients with bipolar disorder. In our study, we found the age of disorder onset to be earlier and number of suicide attempts to be higher in bipolar patients with high dissociation scores. Consequently, it can be said that the results of the present study have supported the results of previous studies.

\section{Limitations}

The present study has some limitations. Firstly, sample size of the present study was relatively smaller. Second limitation of the present study is that the correlation coefficients between our variables were smaller than 0.4. Namely, our results need to confirm with larger sample.

\section{CONCLUSION}

In conclusion, dissociative disorders are frequently observed in bipolar patients. In bipolar disorder patients with childhood trauma or high dissociation scores, the onset of the disease may be earlier and the number of suicide attempts may be greater.

\section{Authorship declaration}

All authors listed meet the authorship criteria according to the latest guidelines of the International Committee of Medical Journal Editors, and all authors are in agreement with the manuscript.

\section{Conflict of interest}

The authors disclosed no conflict of interest during the preparation or publication of this manuscript.

\section{Financing}

The authors disclosed that they did not receive any grant during conduction or writing of this study.

\section{REFERENCES}

[1] Fisher HL, Hosang GM. Childhood maltreatment and bipolar disorder: a critical review of the evidence. Mind Brain 2010;1:750-85. [2] Larsson S, Aas M, Klungsøyr O, Agartz I, Mork E, Steen NE, et al. Patterns of childhood adverse events are associated with clinical characteristics of bipolar disorder. BMC Psychiatry 2013;13:97.

[3] Daruy-Filho L, Brietzke E, Lafer B, Grassi-Oliveira R. Childhood maltreatment and clinical outcomes of bipolar disorder. Acta Psychiatr Scand 2011;124:427-34. 
[4] Etain B, Mathieu F, Henry C, Raust A, Roy I, Germain A, et al. Preferential association between childhood emotional abuse and bipolar disorder. J Trauma Stress 2010;23:376-83.

[5] Janssen I, Krabbendam L, Bak M, Hanssen M, Vollebergh W, De GR, et al. Childhood abuse as a risk factor for psychotic experiences. Acta Psychiatr Scand 2004;109:38-45.

[6] Brown GR, McBride L, Bauer MS, Williford WO; Cooperative Studies Program 430 Study Team. Impact of childhood abuse on the course of bipolar disorder: a replication study in U.S. veterans. J Affect Disord 2005;89:57-67.

[7] Alvarez MJ, Roura P, Oses A, Foguet Q, Sola J, Arrufat FX. Prevalence and clinical impact of childhood trauma in patients with severe mental disorders. J Nerv Ment Dis 2011;199:156-61.

[8] Holowka DV, King S, Sahep D, Pukal M, Brunet A. Childhood abuse and dissociative symptoms in adult schizophrenia. Schizophr Res 2003; 60:87-90.

[9] Zanarini MC, Ruser T, Frankenburg FR, Hennen J. The dissociative experiences of borderline patients. Compr Psychiatry 2000;41:223-7.

[10] Sar V, Taycan O, Bolat N, Ozmen M, Duran A, Ozturk E, et al. Childhood trauma and dissociation in schizophrenia. Psychopathology 2010;43:33-40

[11] Latalova K, Prasko J, Pastucha P, Grambal A, Kamaradova D, Diveky T, et al. Bipolar affective disorder and dissociation - comparison with healthy controls. Biomed Pap Med Fac Univ Palacky Olomouc Czech Repub 2010;155:181-6.

[12] Hariri AG, Yazıcı-Güleç M, Cengiz-Örengül FF, Aydın-Sümbül A, Yeni-Elbay R, Güleç H. Dissociation in bipolar disorder: relationships between clinical variables and childhood trauma. J Affect Disord 2015;184:104-10.

[13] First MB, Spitzer RL, Gibbon M, Williams JBW. Structured Clinical Interview for DSM-IV Axis I Disorders (SCID-I), Clinical Version. Washington: American Psychiatric Press, 1997.

[14] Çorapçıŏ̆lu A, Aydemir O, Yıldız M, Danacı AE, Köroğlu E. DSMIV Eksen-I Bozuklukları için Yapılandırılmış Klinik Görüşme. Ankara: HYB, 1999.

[15] Steinberg M, Cicchetti DV, Buchanan J, Hall PE, Rounsaville B. Clinical assessment of dissociative symptoms and disorders. The Structured Clinical Interview for DSM-IV Dissociative Disorders (SCID-D). Dissociation 1993;6:3-15.

[16] Kundakci T, Şar V, Kiziltan E, Yargic LI, Tutkun H. The reliability and validity of the Turkish Version of the Structured Clinical Interview for DSM-IV Dissociative Disorders (SCID-D): A preliminary study. J Trauma Dissociation 2014;15:24-34.

[17] Bernstein EM, Putnam PW. Development, reliability and validity of a dissociation scale. J Nerv Ment Dis 1986;174:727-35.

[18] Yargı̨̧ LI, Tutkun H, Şar V. The reliability and validity of the Turkish version of the dissociative experiences scale. Dissociation
1995;8:10-3.

[19] Bernstein DP, Fink L, Handelsman L, Foote J, Lovejoy M, Wenzel $\mathrm{K}$, et al. Initial reliability and validity of a new retrospective measure of child abuse and neglect. Am J Psychiatry 1994;151:1132-6.

[20] Şar V, Öztürk E, İkikardeş E. Çocukluk Çağı Ruhsal Travma Ölçeğinin Türkçe uyarlamasının geçerlilik ve güvenilirliği. Turkiye Klinikleri J Med Sci 2012;32:1054-63.

[21] Hyun M, Friedman SD, Dunner DL. Relationship of childhood physical and sexual abuse to adult bipolar disorder. Bipolar Disord 2000;2:131-5.

[22] Leboyer M, Etain B, Mathieu F, Henry C, Jamain S, Bellivier F. Childhood affective trauma in bipolar affective disorder. Bipolar Disord 2007; 9(Suppl 1):9.

[23] Leverich GS, Post RM. Course of bipolar illness after history of childhood trauma. Lancet 2006;367:1040-2.

[24] Garno JL, Goldberg JF, Ramirez PM, Ritzler BA. Impact of childhood abuse on the clinical course of bipolar disorder. $\mathrm{Br} \mathrm{J}$ Psychiatry 2005;186:121-5.

[25] Hammersley P, Dias A, Todd G, Bowen-Jones K, Reilly B, Bentall RP. Childhood trauma and hallucinations in bipolar affective disorder: preliminary investigation. Br J Psychiatry 2003;182:543-7.

[26] Leverich GS, Mcelroy SL, Suppes T, Keck PE, Denicoff KD, Nolen WA, et al. Early physical and sexual abuse associated with an adverse course of bipolar illness. Biol Psychiatry 2002;51:288-297.

[27] Romero S, Birmaher B, Axelson D, Goldstein T, Goldstein BI, Gill MK, et al. Prevalence and correlates of physical and sexual abuse in children and adolescents with bipolar disorder. J Affect Disord 2009;112:144-50.

[28] Heim C, Mletzko T, Purselle D, Muselman DL, Nemeroff CB. The dexamethasone/corticotropin-releasing factor test in men with major depression: role of childhood trauma. Biol Psychiatry 2008;63:398-405. [29] Teicher MH, Anderson CM, Polcari A. Childhood maltreatment is associated with reduced volume in the hippocampal subfields CA3, dentate gyrus, and subiculum. Proc Natl Acad Sci U S A 2012;109:E56372.

[30] Coryell W. Single case study. Multiple personality and primary affective disorder. J Nerv Ment Dis 1983;171:388-390.

[31] Steingard S, Frankel FH. Dissociation and psychotic symptoms. Am J Psychiatry 1985;142:953-5.

[32] Spitzer C, Barnow S, Freyberger HJ, Grabe HJ. Dissociation predicts symptom-related treatment outcome in short-term inpatient psychotherapy. Aust N Z J Psychiatry 2007;41:682-7.

[33] Bakım B, Baran E, Güleken MD, Tankaya O, Yayla S, Akpınar A, et al. Comparison of the patient groups with and without dissociative disorder comorbidity among the inpatients with bipolar disorder. Fam Pract Palliat Care 2016;1:35-42. 